\title{
A study of multidrug-resistant tuberculosis in risk groups in the city of Santos, São Paulo, Brazil
}

\author{
Andréa Gobetti Vieira Coelho', Liliana Aparecida Zamarioli', \\ Maria Alice Telles², Lucilaine Ferrazoli², Eliseu Alves Waldman ${ }^{3 /+}$ \\ ${ }^{1}$ Centro de Laboratório Regional Santos ${ }^{2}$ Núcleo de Tuberculose e Micobactérias, Instituto Adolfo Lutz, São Paulo, SP, Brasil \\ ${ }^{3}$ Faculdade de Saúde Pública, Universidade de São Paulo, São Paulo, SP, Brasil
}

\begin{abstract}
Monitoring the extent of and trends in multidrug-resistant tuberculosis (MDR-TB) is a priority of the Brazilian National Tuberculosis Control Programme. The current study aimed to estimate the incidence of MDR-TB, describe the profile of TB drug resistance in risk groups and examine whether screening for MDR-TB adhered to the recommended guidelines. A descriptive study that examined diagnosed cases of pulmonary TB was conducted in the city of Santos, Brazil, between 2000-2004. Of the 2,176 pulmonary TB cases studied, 671 (30.8\%) met the criteria for drug sensitivity testing and, of these cases, 31.7\% (213/671) were tested. Among the tested cases, 9.4\% were resistant to one anti-TB drug and $15 \%$ were MDR. MDR was observed in $11.6 \%$ of 86 new TB cases and $17.3 \%$ of 127 previously treated cases. The average annual incidence of MDR-TB was 1.9 per 100,000 inhabitants-years. The extent of known MDR-TB in the city of Santos is high, though likely to be underestimated. Our study therefore indicates an inadequate adherence to the guidelines for MDR-TB screening and suggests the necessity of alternative strategies of MDR-TB surveillance.
\end{abstract}

Key words: pulmonary tuberculosis - drug resistance - multidrug resistance - surveillance

Multidrug-resistant tuberculosis (MDR-TB) has been a growing concern among health authorities worldwide because the treatment for MDR-TB is long-term, costly and complex. In addition, MDR-TB increases the rate of hospital admissions and TB-related mortalities (Rossetti et al. 2002).

In 2008, it was estimated that there were 440,000 MDR-TB cases and 150,000 deaths worldwide; $3.6 \%$ of the new TB cases were likely to be associated with multidrug-resistant strains of Mycobacterium tuberculosis (WHO 2010a, b).

In Brazil, there are few population-based studies that have estimated the incidence rate of MDR-TB (Telles et al. 2005). The available data show a range from $1-8 \%$ of all new cases and $3-13 \%$ of previously treated TB patients (Brito et al. 2010, Santos et al. 2010).

The factors that are associated with MDR-TB include prior treatment, cavitary pulmonary TB, treatment failure, inadequate drug regimens, illicit drug use, human immunodeficiency virus (HIV) infection, hospitalisation two years prior to TB diagnosis, diabetes and alcohol dependence (Kritski et al. 1997, Telles et al. 2005, Faustini et al. 2006).

In 2010, the annual TB incidence rate in the state of São Paulo (SP) was estimated to be approximately 40.5 per 100,000 inhabitants-year (MS 2011), which is slightly above the national average ( 38.0 per 100,000 inhabit-

Financial support: CNPq (307728/2009-9), ICOHRTA-AIDS/TB + Corresponding author: eawaldma@usp.br

Received 10 November 2011

Accepted 14 March 2012 ants-year). However, $53 \%$ of new cases were clustered in 10 of 647 municipalities, notably in the city of Santos, which had an incidence rate that was twice as high as the average rate in SP (SES 2011).

Between 2000-2004, 2,176 cases of pulmonary TB were reported in Santos. Of these cases, $23 \%$ of the patients had a past history of TB. The mean prevalence of TB-HIV co-infection was $16 \%$ and the average cure and treatment dropout rates were $71 \%$ and $12 \%$, respectively (Coelho et al. 2009). These data highlight the challenges faced by the Brazilian National Tuberculosis Control Programme (NTCP) and the high prevalence of risk factors for MDR-TB in the city of Santos.

Monitoring the extent of and trends in MDR-TB is a priority for the NTCP. Surveillance systems for MDRTB were implemented in Brazil in 2000 and were based on periodic national surveys and MDR-TB screening of high-risk groups (MS 2007). The current study aimed to estimate the incidence of MDR-TB in the city of Santos, describe the profile of TB drug resistance in risk groups and examine the adherence to the recommended guidelines for MDR-TB screening.

\section{PATIENTS, MATERIALS AND METHODS}

A descriptive study was conducted in the city of Santos. Santos is located within the metropolitan area of Baixada Santista and, in 2010, had an estimated population of 420,000; $99 \%$ of the inhabitants live in the urban area (MPOG 2010). Santos is a priority city for the NTCP, as it has one of the highest incidence rates of TB in SP; Santos had a TB incidence rate of 85.0 per 100,000 inhabitants-year in 2010 (SES 2011). The study population consisted of patients who were diagnosed and treated for pulmonary TB between 2000-2004 and living in Santos from 1 January 2000-31 December 2004. 
Cases of pulmonary TB were defined as individuals of both sexes aged 15 years or older who had clinical symptoms consistent with TB and confirmed by at least one of the following criteria: smear microscopy or culture with isolation of M. tuberculosis or confirmed by evidence of TB by clinical examination and X-rays with findings suggestive of pulmonary cavity.

MDR-TB cases were defined as individuals who, in addition to meeting the pulmonary TB case definition, had strains of M. tuberculosis that were resistant to at least both isoniazid (INH) and rifampicin (RMP) (SBPT 2009).

For the MDR-TB screening with drug sensitivity testing (DST), the NTCP guidelines included testing of high-risk TB patients who exhibited the following characteristics: presence of TB-HIV co-infection, suspected drug resistance due to treatment dropout, treatment failure, TB relapse or contact with an MDR-TB strain, suspected primary drug resistance and inclusion in a highrisk group, such as health providers, the homeless and institutionalised populations (MPOG 2010).

For participation in the study, patients had to meet the DST criteria described above, exhibit pulmonary TB with cultured isolation of $M$. tuberculosis, be undergoing DST, diagnosis and treatment of TB in the city's health services during the study period and be reported to the TB surveillance system of Baixada Santista.

The exclusion criteria included patients that were infected with nontuberculous mycobacteria or patients whose information could not be confirmed in accord with the study criteria.

The data sources used in the study were the TB Surveillance System of Baixada Santista, the Adolfo Lutz Institute, the Santos Regional Laboratory and the Central Laboratory. The Brazilian Institute of Geography and Statistics was used to collect the demographic data.

The following variables were studied: sociodemographic characteristics, current and past history of TB and aspects related to TB diagnosis, treatment and comorbidities.

Laboratory techniques - Sputum samples were digested and decontaminated using the Petroff method and were inoculated into Lowenstein-Jensen medium. The samples were subsequently incubated at $37^{\circ} \mathrm{C}$ for 60 days and examined weekly. The cultures were scored negative if there was no growth within 60 days. The isolated mycobacteria were identified based on their biochemical properties (MS 2008).

Drug resistance was tested by the resistance ratio method for INH, RMP, streptomycin and ethambutol. For pyrazinamide, resistance was tested by the pyrazinamidase test (Jenkins et al. 1985).

Data analysis - The database obtained from the TB surveillance system was formatted for use with Epi Info version 6.4 software. The data were first analysed for consistency and duplicates and cases that did not meet the study criteria were excluded. The laboratory data were compared against the Adolfo Lutz Institute database and were corrected and completed as needed. Analyses were performed with the Statistical Package for Social Sciences version 15 and the variables were reclassified when appropriate.
For descriptive data analysis and group comparisons, the chi-square and Fisher's exact tests were used for categorical variables and the Kruskal-Wallis test was used for continuous variables.

The patients with pulmonary $\mathrm{TB}$ who met the screening criteria for DST were first compared with the patients who did not met the criteria; subsequently the patient who met the screening criteria and undergo DST were compared with the patients who met the screening criteria and did not undergo DST. Finally, the drug resistance profiles of the patients undergoing DST were analysed, comparing the drug resistance profiles among the new TB cases with patients who had a past history of TB.

The average annual incidence rate of drug resistance for the period between 2000-2004 was calculated by dividing the number of patients with any type of resistance by the number of individuals in the population that were aged 15 years or older and were living in Santos at the midpoint of the study; next, the resulting number was divided by five. Based on reports in the literature, the prevalence of the risk factors for MDR-TB was estimated in patients with strains that were sensitive to all the drugs tested and in patients with different drug resistance profiles.

The current study was approved by the Research Ethical Committee of the Adolfo Lutz Institute (protocol 25/06).

\section{RESULTS}

Based on the study criteria, a total of 2,176 cases of pulmonary TB were identified in the city of Santos between January 2000-December 2004. Among the cases, $30.8 \%(671 / 2,176)$ met the criteria for DST (i.e., had risk factors for MDR-TB) and 31.7\% (213/671) of these individuals actually underwent testing. Of those undergoing DST, 59.6\% (127/213) had a prior history of TB treatment (Figure). The proportion of patients actually undergoing testing among all those who met the criteria for DST remained constant during the study period.

There were no significant differences in the sociodemographic characteristics of patients who met and patients who did not meet the criteria for DST. However, a higher rate of supervised treatment $(67.1 \%$ vs. $61.7 \%$, $\mathrm{p}=0.017)$ and hospitalisation during treatment $(42.8 \%$ vs. $30.4 \%, p<0.0001)$ and a lower prevalence of diabetes $(5.4 \%$ vs. $9.8 \%, \mathrm{p}=0.001)$ were observed among patients who met the criteria for DST. However, in the same group, the cure rate was lower $(64 \%$ vs. $86 \%$, p $<0.001)$ and the proportion of unfavourable outcomes [dropout, death due to TB or acquired immune deficiency syndrome (AIDS) and treatment failure] was higher $(36 \%$ vs. $14 \%, \mathrm{p}<0.001)$.

The data available on the 671 patients who met the criteria for DST showed that $61.8 \%(400 / 647)$ had a past history of TB and 50.8\% (332/653) were co-infected with HIV. Among those with a past history of TB, $60.2 \%$ (240/399) were treatment dropouts (Table I).

In a comparison between patients undergoing (213/671) and patients not undergoing DST (468/671), the patients undergoing DST showed a lower proportion 


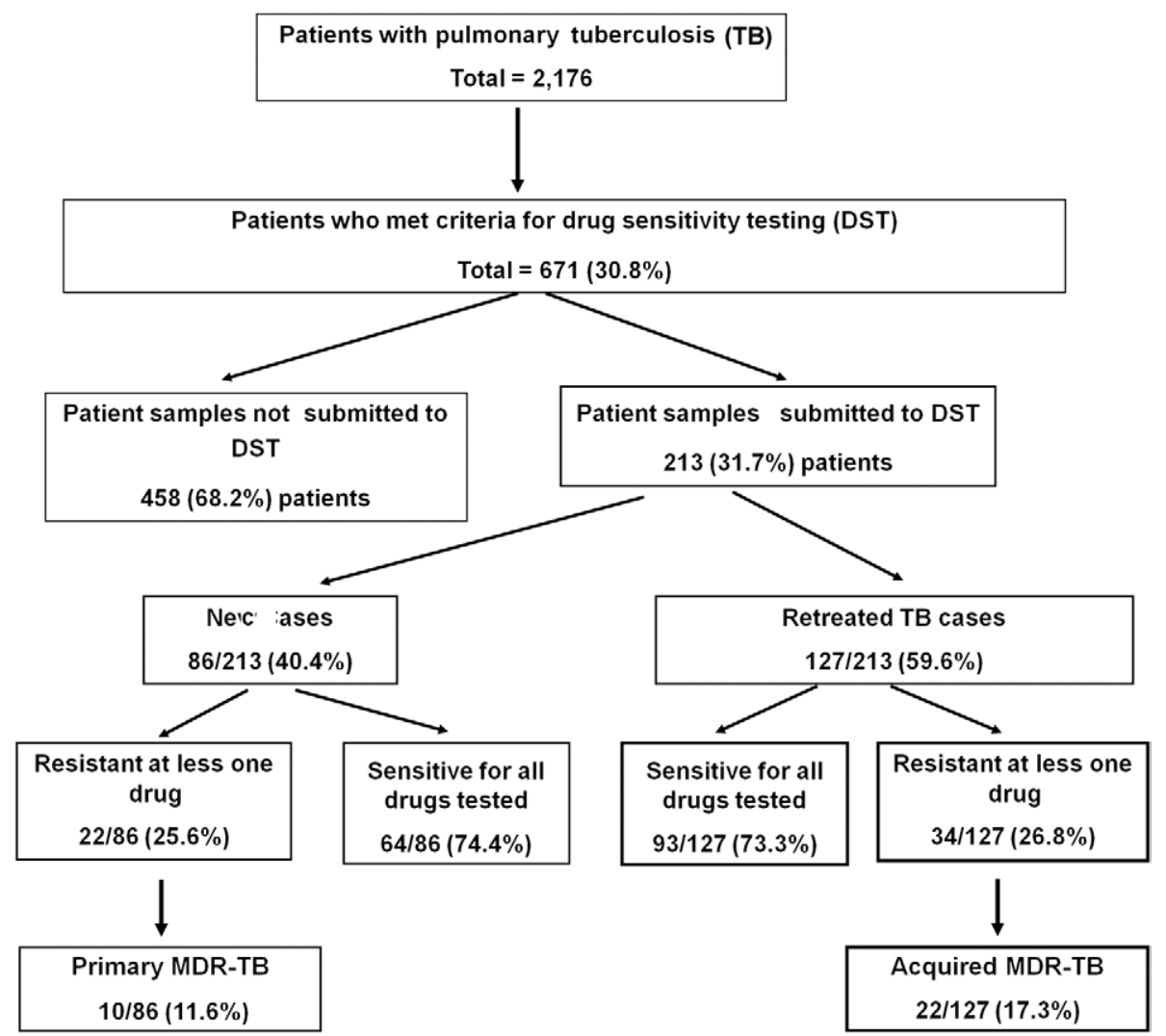

Flowchart of the study population and its distribution according to characteristics of patient samples undergoing DST, Santos, Brazil, 20002004. MDR: multidrug resistant.

of TB-HIV co-infection ( $39.2 \%$ vs. $56.3 \%, \mathrm{p}<0.003)$, a higher proportion of patients with cavitary pulmonary lesions $(31.9 \%$ vs. $15.1 \%, p<0.001)$ and a higher proportion of patients that changed treatment regimens $(12.2 \%$ vs. $3.4 \%, \mathrm{p}<0.0001)$. Regarding the outcomes, there were no differences between the groups (Table I). However, the proportion of supervised treatment was higher among those undergoing DST $(77.3 \%$ vs. $62.4 \%, \mathrm{p}<0.0001)$.

Of the patients with pulmonary TB who underwent DST $(n=213), 73.7 \%(157 / 213)$ were sensitive to all of the drugs tested, $9.4 \%(20 / 213)$ were resistant to one drug and $15 \%(32 / 213)$ were MDR. Of all of the patients who underwent DST $(\mathrm{n}=213), 86(40.4 \%)$ were new cases, of which $74.4 \%(64 / 86)$ were sensitive to all the drugs tested, $11.6 \%$ (10/86) were resistant to one drug and $11.6 \%$ $(10 / 86)$ were primary MDR-TB cases. In contrast, of the $127 / 213(59.6 \%)$ cases with a prior history of TB treatment, $73.3 \%(93 / 127)$ were sensitive to all the drugs tested, $7.8 \%(10 / 127)$ were resistant to one drug and $17.3 \%$ (22/127) were acquired MDR-TB cases (Table II).

A comparison of the primary MDR-TB cases with the acquired MDR-TB cases showed a higher cure rate in the former group ( $70 \%$ vs. $31.8 \%, p=0.008)$ and this rate was slightly lower than that observed in patients who did not meet the criteria for DST.

Among the MDR-TB cases, most were males (78\%; $25 / 32)$ between the ages of 20-49 (79\%) with a median age of 39.2 years. TB-HIV co-infection was present in
$22 \%(7 / 32)$ of the cases and $68.7 \%(22 / 32)$ of the patients had a past history of TB. A change in the treatment regimen was reported in $47 \%(14 / 30)$ of the cases and supervised treatment was provided in $75 \%(24 / 32)$ of the cases. Among these patients, $43.8 \%(14 / 32)$ were cured, $31.2 \%(10 / 32)$ dropped out of the TB treatment, $15.6 \%$ $(5 / 32)$ died from TB, $3.1 \%(1 / 32)$ died from other causes and $6.4 \%(2 / 32)$ had treatment failure.

A comparison of the prevalence of the risk factors for TB drug resistance between the cases that were sensitive to all the drugs tested and the cases that exhibited MDR-TB showed that the latter had a lower proportion of TB-HIV co-infection ( $21.9 \%$ vs. $43.9 \%, \mathrm{p}<0.05)$, a higher proportion of individuals that changed treatment regimens $(43.7 \%$ vs. $3.8 \%, p<0.05)$ and a higher proportion of cavitary pulmonary lesions $(46.9 \%$ vs. $24.8 \%$, p $<0.05$ ) (Table III).

Based on the cases identified in the study, the average annual incidence rate of MDR-TB in the city of Santos was 1.9 per 100,000 inhabitants-year. For females, the incidence rate was 0.75 per 100,000 -year in females and for males, the rate was 3.26 per 100,000 inhabitants-year in males. The annual incidence rates for of primary and acquired MDR-TB were 0.6 and 1.3 per 100,000 inhabitants-year, respectively. The average annual incidence rates of primary and acquired resistance to one or more TB drugs were 1.4 and 1.9 per 100,000 inhabitants-year, respectively. 


\section{DISCUSSION}

The city of Santos is characterised by an almost exclusively urban population with a high population density and favourable socioeconomic indicators. It is among the three largest metropolitan areas in SP and is the largest port in Latin America. Santos ranks fifth among Brazilian cities with the highest Human Development Index (0.871) and has an extensive network of public health services. According to the Brazilian Health Policy, Santos provides universal free access to TB diagnosis and treatment (MPOG 2010). However, the characteristics of TB in this city are similar to those observed in hyperendemic areas (Coelho et al. 2009), with programmatic indicators potentially associated with higher risk for occurrence of MDR-TB.

The results of the current study corroborate the poor programmatic indicators found in Santos during the study period. One-third of TB cases reported between 2000-2004 had risk factors for MDR-TB, which is a proportion that is similar to that reported in a low-income community with high TB rates in the city of São Paulo (Telles et al. 2005), but much higher than that found in the state of Mato Grosso do Sul, in central-western

TABLE I

Characteristics of patients with pulmonary tuberculosis (TB) who met the criteria for tuberculosis drug susceptibility testing (DST), Santos, Brazil, 2000-2004

\begin{tabular}{|c|c|c|c|c|}
\hline \multirow[b]{2}{*}{ Characteristics } & \multicolumn{2}{|c|}{ Underwent DST } & \multirow[b]{2}{*}{$\begin{array}{c}\text { Total } \\
(\mathrm{n}=671) \\
\mathrm{n}(\%)\end{array}$} & \multirow[b]{2}{*}{$\mathrm{p}$} \\
\hline & $\begin{array}{c}\text { Yes } \\
(\mathrm{n}=213) \\
\mathrm{n}(\%)\end{array}$ & $\begin{array}{c}\text { No } \\
(\mathrm{n}=458) \\
\mathrm{n}(\%)\end{array}$ & & \\
\hline Gender & & & & 0.23 \\
\hline Female & $57(27.4)$ & $143(31.2)$ & $200(29.8)$ & - \\
\hline Male & $156(73.2)$ & $315(68.8)$ & $471(70.2)$ & - \\
\hline \multicolumn{5}{|l|}{ Age (years) } \\
\hline $15-19$ & $4(1.9)$ & $10(2.2)$ & $14(2.1)$ & 0.76 \\
\hline $20-49$ & $167(78.4)$ & $368(80.3)$ & $535(79.7)$ & - \\
\hline 50 or more & $42(19.7)$ & $80(17.5)$ & $122(18.2)$ & - \\
\hline Schooling & & & & 0.28 \\
\hline Up to 7 years & $61(34.7)$ & $162(44.6)$ & $223(41.4)$ & - \\
\hline 8 years or more & $115(65.3)$ & $201(55.4)$ & $316(58.6)$ & - \\
\hline Alcohol dependence & & & & 0.14 \\
\hline No & $166(83)$ & $379(87.7)$ & $545(86.2)$ & - \\
\hline Yes & $34(17)$ & $53(12.3)$ & $87(13.8)$ & - \\
\hline HIV infection & & & & $<0.0003$ \\
\hline No & $127(60.8)$ & $194(43.7)$ & $321(49.2)$ & - \\
\hline Yes & $82(39.2)$ & $250(56.3)$ & $332(50.8)$ & - \\
\hline Past history of TB & & & & 0.25 \\
\hline No & $86(40.4)$ & $161(37.1)$ & $247(38.2)$ & - \\
\hline Yes & $127(59.6)$ & $273(62.9)$ & $400(61.8)$ & - \\
\hline Outcome of prior TB treatment & & & & 0.57 \\
\hline Cure & $45(35.7)$ & $114(41.8)$ & $159(39.8)$ & - \\
\hline Dropout & $81(64.3)$ & $159(58.2)$ & $240(60.2)$ & - \\
\hline Relapse & & & & 0.27 \\
\hline No & $169(82)$ & $300(76.0)$ & $499(78)$ & - \\
\hline Yes & $37(18)$ & $104(24.0)$ & $141(22)$ & - \\
\hline Cavitary pulmonary lesions & & & & $<0.0001$ \\
\hline No & $128(68.1)$ & $331(84.9)$ & $459(79.4)$ & - \\
\hline Yes & $60(31.9)$ & $59(15.1)$ & $119(20.6)$ & - \\
\hline Treatment regimen & & & & $<0.0001$ \\
\hline Unchanged & $173(87.8)$ & $422(96.6)$ & $595(93.8)$ & - \\
\hline Changed & $24(12.2)$ & $15(3.4)$ & $39(6.2)$ & - \\
\hline \multicolumn{5}{|l|}{ Treatment completion } \\
\hline Cure & $127(67.2)$ & $255(62.3)$ & $382(63.9)$ & 0.24 \\
\hline Unfavourable outcome $^{a}$ & $63(32.8)$ & $154(37.7)$ & $217(36.1)$ & - \\
\hline
\end{tabular}

$a$ : dropout, deaths from TB and acquired immune deficiency syndrome, treatment failure; HIV: human immunodeficiency virus. Inconsistencies between total patients studied and total variables are due to missing information. 
Brazil (Marques et al. 2010). Notably, only 30\% of the high-risk patients were screened for MDR-TB, suggesting an operational challenge to adhering to the NTCP guidelines. According to the 2007 national data, the challenges in Santos are similar to those generally present nationwide (Kritski 2010). These results highlight the need to increase directly observed treatment shortcourse coverage and provide ongoing training for the teams that are responsible for TB control. In addition, in medium-sized and large cities, the team should include an epidemiologist who will monitor performance indicators and compliance with the programme's guidelines and recommendations.

The incidence rate of MDR-TB in Santos is concerning not only because it is notably high (at least $1.5 \%$ of all pulmonary TB cases in the city), but because it is likely to be an underestimate, as it represents only the cases

\section{TABLE II}

Drug resistance profiles of isolates from 213 patients with pulmonary tuberculosis (TB) confirmed by isolation of Mycobacterium tuberculosis and who underwent drug susceptibility testing, Santos, Brazil, 2000-2004

\begin{tabular}{|c|c|c|c|}
\hline Characteristics & $\begin{array}{c}\text { New cases } \\
(\mathrm{n}=86) \\
\mathrm{n}(\%)\end{array}$ & $\begin{array}{c}\text { Prior TB } \\
\text { treatment } \\
(\mathrm{n}=127) \\
\mathrm{n}(\%)\end{array}$ & $\begin{array}{c}\text { Total } \\
(\mathrm{n}=213) \\
\mathrm{n}(\%)\end{array}$ \\
\hline Sensitive to all drugs & $64(74.4)$ & $93(73.2)$ & $157(73.7)$ \\
\hline Resistant to any drug & $22(25.6)$ & $34(26.7)$ & $56(26.3)$ \\
\hline IHN & $19(22.1)$ & $31(24.4)$ & $50(23.5)$ \\
\hline RMP & $11(12.8)$ & $24(18.9)$ & $35(16.4)$ \\
\hline PZA & $6(7)$ & $14(11)$ & $20(9.4)$ \\
\hline SM & $5(5.8)$ & $6(4.7)$ & $11(5.2)$ \\
\hline EM & $3(3.5)$ & $7(5.5)$ & $10(4.7)$ \\
\hline Resistant to one drug & $10(11.6)$ & $10(7.8)$ & $20(9.4)$ \\
\hline IHN & $7(8.1)$ & $7(5.5)$ & $14(6.6)$ \\
\hline RMP & $1(1.2)$ & $2(1.6)$ & $3(1.4)$ \\
\hline SM & $1(1.2)$ & - & $1(0.5)$ \\
\hline EM & $1(1.2)$ & $1(0.8)$ & $2(0.9)$ \\
\hline MDR & $10(11.6)$ & $22(17.3)$ & $32(15)$ \\
\hline $\mathrm{INH}+\mathrm{RMP}$ & $4(4.7)$ & $6(4.7)$ & $10(4.7)$ \\
\hline $\mathrm{INH}+\mathrm{RMP}+\mathrm{PZA}$ & $2(2.3)$ & $8(6.3)$ & $10(4.7)$ \\
\hline $\mathrm{INH}+\mathrm{RMP}+\mathrm{PZA}+\mathrm{SM}$ & $3(3.5)$ & $1(0.8)$ & $4(1.9)$ \\
\hline $\mathrm{INH}+\mathrm{RMP}+\mathrm{PZA}+\mathrm{EM}$ & $1(1.2)$ & $3(2.4)$ & $4(1.9)$ \\
\hline $\mathrm{INH}+\mathrm{RMP}+\mathrm{PZA}+\mathrm{SM}+\mathrm{EM}$ & - & $1(0.8)$ & $1(0.5)$ \\
\hline $\mathrm{INH}+\mathrm{RMP}+\mathrm{SM}$ & - & $1(0.8)$ & $1(0.5)$ \\
\hline $\mathrm{INH}+\mathrm{RMP}+\mathrm{SM}+\mathrm{EM}$ & - & $2(1.6)$ & $2(0.9)$ \\
\hline Other drug resistance profiles & $2(2.3)$ & $2(1.6)$ & $4(1.9)$ \\
\hline $\mathrm{INH}+\mathrm{PZA}$ & - & $1(0.8)$ & $1(0.5)$ \\
\hline $\mathrm{INH}+\mathrm{EM}+\mathrm{SM}$ & - & $1(0.8)$ & $1(0.5)$ \\
\hline $\mathrm{INH}+\mathrm{SM}$ & $1(1.2)$ & - & $1(0.5)$ \\
\hline $\mathrm{INH}+\mathrm{EM}$ & $1(1.2)$ & - & $1(0.5)$ \\
\hline
\end{tabular}

EM: ethambutol; INH: isoniazide; MDR: multidrug resistant; PZA: pyrazinamide; RMP: rifampicin; SM: streptomycin; TB: tuberculosis. that were identified in one-third of the risk groups. The remaining two-thirds of the cases shared features with those cases undergoing DST, including most risk factors for MDR-TB (Kritski et al. 1997, Telles et al. 2005, Faustini et al. 2006) and unfavourable outcomes.

We found that there was a higher incidence of primary and acquired resistance to INH or RMP and primary and acquired MDR-TB than what was reported in the preliminary data from the Second National Survey of Anti-Tuberculosis Drug Resistance, which was conducted in seven Brazilian states, as well as in other recent studies in Brazil (Ferrazoli et al. 2000, Telles et al. 2005, Souza et al. 2006, Kritski 2010, Marques et al. 2010) and in developing countries (WHO 2010a). In contrast with other Brazilian studies (Telles et al. 2005, Kritski 2010, Marques et al. 2010), the prevalence of primary and acquired resistance is quite similar in Santos, indicating that MDR-TB is a more serious problem in the city. Primary drug resistance is a sensitive indicator for evaluating the performance of the NTCP because the higher the primary drug resistance, the greater the risk of spreading resistant strains in the community (WHO 2010b).

The cases of MDR-TB that were identified in Santos were similar to those described in other studies conducted in Brazil (Telles et al. 2005, Dalcomo et al. 2007, Vieira et al. 2007, Brito 2010, Santos 2010) in that the cases involved predominantly working-age males and two-thirds of the cases had a prior history of TB treatment. Supervised treatment was lower than that recommended by the NTCP. The cure rate was low $(40 \%)$, but it was higher among the primary MDR-TB cases (70\%). The proportion of unfavourable outcomes was notably high and one-fifth of the patients died. In light of this scenario and bearing in mind that these proportions are likely to be an underestimate, TB drug resistance should be a priority for the NTCP and will require strategies specifically designed for hyperendemic TB areas.

The patients with MDR-TB had a higher prevalence of cavitary pulmonary lesions and clinically suspected drug resistant TB than the patients with strains that were sensitive to all the drugs. These findings are plausible, as certain groups (Barroso et al. 2003) consider cavitary pulmonary lesions to be a risk factor for MDR-TB.

The prevalence of HIV infection was higher among patients with strains that were sensitive to all the drugs tested than in patients with MDR-TB. Such a finding deserves comment. The prevalence of TB-HIV co-infection in MDR-TB cases in our study was higher than that reported in other studies conducted in SP (Melo et al. 2003, Telles et al. 2005), but was similar to that found in another study in the metropolitan area of Santos (Rozman et al. 2007). These inconsistencies may be explained by the fact that Santos is a port city and has one of the highest rates of HIV/AIDS in SP (SES 2010).

Although several studies showed an association between TB-HIV co-infection and MDR-TB (Faustini et al. 2006, Haar et al. 2007), thereby supporting the NTCP recommendation for routine DST for all HIV-infected patients, no evidence of an association was found in our study. This finding corroborates other studies that have 
TABLE III

Prevalence of risk factors for tuberculosis (TB) drug resistance among 213 cases of pulmonary tuberculosis undergoing drug susceptibility testing (DST), Santos, Brazil, 2000-2004

\begin{tabular}{|c|c|c|c|c|c|}
\hline \multirow[b]{3}{*}{$\begin{array}{l}\text { Criteria for drug } \\
\text { susceptibility testing }\end{array}$} & \multicolumn{4}{|c|}{$\begin{array}{c}\text { DST results } \\
\mathrm{n}(\%)\end{array}$} & \multirow[b]{3}{*}{$\begin{array}{c}\text { Total } \\
(\mathrm{n}=213)\end{array}$} \\
\hline & \multicolumn{3}{|c|}{$\begin{array}{l}\text { Resistant } \\
(\mathrm{n}=56)\end{array}$} & \multirow[b]{2}{*}{$\begin{array}{l}\text { Sensitive } \\
(\mathrm{n}=157)\end{array}$} & \\
\hline & $\begin{array}{l}\text { Any drug resistance } \\
\text { except for } \mathrm{MDR}^{a} \\
\qquad(\mathrm{n}=24)\end{array}$ & $\begin{array}{l}\mathrm{MDR}^{b} \\
(\mathrm{n}=32)\end{array}$ & $\begin{array}{l}\text { All drug } \\
\text { resistances } \\
(n=56)\end{array}$ & & \\
\hline Dropout & $10(41.6)$ & $15(46.9)$ & $25(44.6)$ & $56(35.7)$ & $81(38.1)$ \\
\hline Relapse & $2(8.3)$ & $6(18.7)$ & $8(14.3)$ & $29(18.5)$ & $37(17.4)$ \\
\hline HIV infection & $6(25)$. & $7(21.9)^{d}$ & $13(23.2)$ & $69(43.9)^{d}$ & $82(39.2)$ \\
\hline Clinically suspected resistance ${ }^{c}$ & $4(16.7)$ & $14(43.7)^{d}$ & $17(30.3)$ & $6(3.8)^{d}$ & $48(22.5)$ \\
\hline Past history of TB & $12(50)$ & $22(68.7)$ & $36(64.3)$ & $93(59.2)$ & $127(59.6)$ \\
\hline Health provider & $1(4.2)$ & - & $1(1.8)$ & $2(1.3)$ & $3(1.4)$ \\
\hline Alcohol dependence & $4(16.7)$ & $8(25)$ & $12(21.4)$ & $22(14)$ & $36(16.9)$ \\
\hline Supervised treatment & $18(75)$ & $24(75)$ & $42(75)$ & $121(77.1)$ & $163(76.5)$ \\
\hline Diabetes & $1(4.1)$ & $3(9.4)$ & $4(7.1)$ & $5(3.4)$ & $9(4.2)$ \\
\hline Cavitary pulmonary lesions & $6(25)$ & $15(46.9)^{d}$ & $21(37.5)$ & $39(24.8)^{d}$ & $60(28.2)$ \\
\hline
\end{tabular}

$a$ : resistant to at least one of five drugs tested or other type of resistance [drug resistance profile other than multidrug resistant (MDR) or resistant to one drug]; $b$ : resistant to at least isoniazid and rifampicin whether or not associated with other drugs; $c$ : patients whose treatment regimen was changed; $d$ : $<<0.05$; HIV: human immunodeficiency virus.

been conducted in Brazil (Barroso et al. 2003, Telles et al. 2005) and is supported by a recent systematic literature review (Suchindran et al. 2009).

When interpreting the results of our study, several limitations of the study need to be acknowledged. The study was based on secondary data, which can often be incomplete and only data from a third of the at-risk population for TB drug resistance were analysed. Despite these limitations, our results are consistent with the literature and allowed us to estimate the extent and examine the profile of TB drug susceptibility among the high-risk MDR-TB patients. Such data can be used to develop targeted control strategies.

The findings of this study support at least three major recommendations: (i) to develop strategies to improve the surveillance of MDR-TB in hyperendemic areas (e.g., a citywide sentinel surveillance system), (ii) to investigate whether TB-HIV co-infection is associated with MDR-TB in Brazil and (iii) given the high rates of primary drug resistance found, patients and their household contacts should be monitored for two years after completing treatment and a strategy should be developed to contact TB patients who have dropped out of their treatment protocol.

\section{ACKNOWLEDGEMENTS}

To the TB surveillance teams in Santos and SP, as well as staff working at Santos Regional Laboratory of Adolfo Lutz Institute and Mycobacteria Laboratory of the Adolfo Lutz Institute Central Laboratory, SP, for allowing access to their databases.

\section{REFERENCES}

Barroso EC, Mota RMS, Santos ROP, Sousa ALO, Barroso, JBB, Rodrigues JLN 2003. Risk factors for acquired multidrug-resistant tuberculosis. J Pneumol 29: 89-97.

Brito RC, Mello FC, Andrade MK, Oliveira H, Costa W, Matos HJ, Lourenço MC, Rolla VC, Fonseca L, Ruffino Netto A, Kritski AL 2010. Drug-resistant tuberculosis in six hospitals in Rio de Janeiro, Brazil. Int J Tuberc Lung Dis 14: 24-33.

Coelho AGV, Zamarioli LA, Perandones CA, Cuntiere I, Waldman EA 2009. Características da tuberculose pulmonar em área hiperendêmica - município de Santos (SP). J Bras Pneumol 35: 998-1007.

Dalcomo MP, Andreade MKN, Picon PD 2007. Tuberculose multirresistente no Brasil: histórico e medidas de controle. Rev Saude Publica 41 (Suppl. 1): 34-42.

Faustini A, Hall AJ, Perucci CA 2006. Risk factors for multidrug resistant tuberculosis in Europe: a systematic review. Thorax 61: $158-163$.

Ferrazoli L, Palaci M, Marques LRM 2000. Transmission of tuberculosis in an urban setting in Brazil. Int J Tuberc Lung Dis 4: 18-25.

Haar CH, Cobelens FGJ, Kalisvaart NA, Van der Have JJ, Van Gerven PJHJ, Van Soolingens D 2007. Tuberculosis drug resistance and HIV infection. The Netherlands. Emerg Infect Dis 13: 776-778.

Jenkins PA, Duddridge LR, Collins CH, Yates MD 1985. Mycobacteria. In CH Collins, JM Grange (eds.), Isolation and identification of micro-organisms of medical and veterinary importance, Academic Press, London, p. 275-296.

Kritski AL 2010. Emergência de tuberculose resistente: renovado desafio. J Bras Pneumol 36: 157-158. 
Kritski AL, Rodrigues de Jesus LS, Andrade MK, Werneck-Barroso E, Vieira MAMS, Haffner A, Riley LW 1997. Retreatment tuberculosis cases factors associated with drug resistance and adverse outcomes. Chest 111: 1162-1167.

Marques M, Cunha EAT, Ruffino-Neto A, Andrade SMO 2010. Perfil de resistência de Mycobacterium tuberculosis no estado de Mato Grosso do Sul, 2000-2006. J Bras Pneumol 36: 224-231.

Melo FAF, Afiune JB, Neto IJ, Almeida EA, Spada DTA, Antelmo ANL, Cruz ML 2003. Aspectos epidemiológicos da tuberculose multirresistente em serviço de referência na cidade de São Paulo. Rev Soc Bras Med Trop 36: 27-34.

MS - Ministério da Saúde/Secretaria Nacional de Vigilância em Saúde 2007. Sistema de vigilância epidemiológica da tuberculose multiresistente. Rev Bras Pneumol Sanit 15: 39-46.

MS - Ministério da Saúde/Secretaria de Vigilância em Saúde/Departamento de Vigilância Epidemiológica 2008. Manual nacional de vigilância laboratorial da tuberculose e outras micobactérias, MS, Brasília, 436 pp.

MS - Ministério da Saúde/Sistema Nacional de Agravos de Notificação 2011. Taxas de incidência de tuberculose. [accessed 11 May 2011]. Available from: portal.saude.gov.br/portal/arquivos/pdf/ taxa_incidencia_tuberculose.pdf.

MPOG - Ministério do Planejamento, Orçamento e Gestão/Instituto Brasileiro de Geografia e Estatística 2010. Censo Demográfico. Primeiros resultados. Cidades. [accessed 17 December 2010]. Available from: ftp://ibge.gov.br/cidades.

Rossetti MLR, Valim ARM, Silva MSN, Rodrigues VS 2002. Tuberculose resistente: revisão molecular. Rev Saude Publica 36: 525-532.

Rozman LM, Santo AH, Rozman MA 2007. Resistência do Mycobacterium tuberculosis às drogas em pacientes $\mathrm{HIV}^{+}$em cinco municípios da Baixada Santista, São Paulo, Brasil. Cad Saude Publica 23: 1051-1059.

Santos LC, Bousquet HM, Pereira AM, Junqueira-Kipnis AP, Kipnis A 2010. A high prevalence of resistance in new tuberculosis cases of midwestern Brazil. Infect Genet Evol 10: 1052-1057.
SES - Secretaria de Estado da Saúde São Paulo/Coordenadoria de Controle de Doenças/Coordenação Estadual de DST/AIDS/Divisão de Vigilância Epidemiológica 2010. Boletim Epidemiológico 27. Available from: crt.saude.sp.gov.br/iec/boletim2010.pdf.

SES - Secretaria de Estado da Saúde São Paulo/Coordenadoria de Controle de Doenças/Centro de Vigilância Epidemiológica Prof. Alexandre Vranjac/Divisão de Controle da Tuberculose 2011. Tuberculose em números. [accessed 28 August 2011]. Available from: cve.saude.sp.gov.br/htm/cve_tb.html.

SBPT - Sociedade Brasileira de Pneumologia e Tisiologia/Comissão de Tuberculose/Grupo de Trabalho das Diretrizes para Tuberculose 2009. III Diretrizes para Tuberculose da SBPT. J Bras Pneumol 35: 1018-1048.

Souza MB de, Antunes CM de F, Garcia GF 2006. Perfil de sensibilidade e fatores de risco associados à resistência do Mycobacterium tuberculosis em centro de referência de doenças infectocontagiosas de Minas Gerais. J Bras Pneumol 32: 430-437.

Suchindran S, Brouwer ES, Van Rie A 2009. Is HIV infection a risk factor for multi-drug resistant tuberculosis? A systematic review. PloS ONE 4: 1-9.

Telles MAS, Ferrazoli L, Waldman EA, Giampaglia CMS, Martins MC, Ueki SYM, Chimara E, Silva CA, Cruz V, Walkman CCS, Heyn I, Uehara Hirono I, Riley LW 2005. A population-based study of drug resistance and transmission of tuberculosis in an urban community. Int J Tuberc Lung Dis 9: 970-976.

Vieira R da CA, Fregona G, Palaci M, Dietze R, Maciel ELN 2007. Perfil epidemiológico dos casos de tuberculose multirresistente do Espírito Santo. Rev Bras Epidemiol 10: 56-65.

WHO - World Health Organization 2010a. Global tuberculosis control: WHO report 2010. Available from: who.int/tb/publications/ global_report/archive/en/index.html.

WHO - World Health Organization 2010b. Multidrug and extensively drug-resistant TB (M/XDR-TB): 2010 global report on surveillance and response. Available from: whqlibdoc.who.int/ publications/2010/9789241599191_eng.pdf. 